\title{
PENGEMBANGAN LEARNING MANAGEMENT SYSTEM (LMS) DALAM IMPLEMENTASI MEDIA PEMBELAJARAN DI PERGURUAN TINGGI
}

\author{
Penulis \\ Rahabistara Tito Hardika \\ Institusi \\ Magister Teknologi Pendidikan, Universitas Muhammadiyah Jakarta \\ Email Korespondensi \\ titohardika@gmail.com
}

DOI

10.53947/perspekt.v1i2.14

Kata Kunci:

Sistem Manajemen Pembelajaran Media Pembelajaran Rencana Pembelajaran Semester

Keywords:

Learning Management System Learning Media Semester Lesson Plan

\begin{abstract}
Abstrak
Semakin berkembang pesatnya teknologi sejalan pula dengan semakin berkembangnya kualitas Pendidikan khusunya jenjang Perguruan Tinggi. Pembelajaran daring atau online melalui elearning yang biasa disebut Learning Management System (LMS) merupakan cerminan kualitas dari Perguruan Tinggi yang mana harus mampu memanfaatkan peran terknologi tersebut untuk dapat mengembangkan model pembelajaran jarak jauh. Pengembangan LMS harus didesain dan dikembangkan secara maksimal untuk menunjang segala keperluan yang dibutuhkan pengguna LMS tersebut yaitu mahasiswa, dosen, dan tenaga kependidikan. Pengembangan LMS ini disusun berdasarkan model ADDIE yaitu dengan Analysis, Design, Development or Production, Implementation or Delivery, and Evaluation. Hasil rancangan berupa menganalisis kompetensi, analisis karakteristik sumber daya manusia (SDM), dan analisis instruksional yang mana dari Perguruan Tinggi menemukan permasalahan di lapangan terkait penggunaan LMS sebagai media pembelajaran. Berdasarkan hasil analisis, maka diputuskan bahwa rencana pembelajaran semester (RPS) adalah desain pokok untuk mengembangkan LMS yang mana RPS harus sesuai dan memuat skema pembelajaran semester serta capaian pembelajaran mata kuliah, sehingga seluruh dosen akan mengikuti pelatihan pembuatan RPS yang muatan materinya disesuaikan dengan kebutuhan para dosen dalam penggunaan LMS sebagai media pembelajaran. Berdasarkan hasil analisis dan desain yang telah disusun maka tim pengembangan Learning Management System (LMS) melakukan kajian materi dan mengembangkan modul pelatihan penggunaan LMS dengan mengidentifikasi fiturfitur yang ada bagi dosen dan mahasiswa. Selanjutnya adalah menerapkan sistem dan desain pelatihan pengembangan serta penggunaan LMS yang telah disusun sehingga tujuan - tujuan yang telah ditetapkan sebelumnya bisa tercapai dengan baik. Setelah itu dilakukan evaluasi untuk seluruh materi yang telah diberikan dalam penggunaan dan pengembangan LMS serta masukan terkait kendala serta tambahan fitur di LMS oleh pengguna.
\end{abstract}

\section{Abstract}

The rapid development of technology is also in line with the development of the quality of education, especially at the higher education level. Online learning or online through e-learning which is commonly called Learning Management System (LMS) is a reflection of the quality of Higher Education which must be able to take advantage of the role of technology to be able to develop distance learning models. LMS development must be designed and developed optimally to support all the needs needed by the LMS 
users, namely students, lecturers, and education staff. The development of this LMS is based on the ADDIE model, namely Analysis, Design, Development or Production, Implementation or Delivery, and Evaluation. The results of the design are in the form of analyzing competencies, analyzing the characteristics of human resources (HR), and instructional analysis which universities find problems in the field related to the use of LMS as a learning medium. Based on the results of the analysis, it was decided that the semester learning plan (RPS) is the main design for developing an $L M S$ in which the RPS must be appropriate and contain the semester learning scheme and the learning outcomes of the courses, so that all lecturers will attend training in making RPS whose material content is adjusted to the needs of the students. lecturers in using LMS as a learning medium. Based on the results of the analysis and design that have been prepared, the Learning Management System (LMS) development team conducts a material review and develops a training module for using the LMS by identifying the features available for lecturers and students. Next is to implement the system and design of development training and use of the LMS that has been prepared so that the goals that have been previously set can be achieved properly. After that, an evaluation is carried out for all the materials that have been provided in the use and development of the LMS as well as input related to obstacles and additional features in the LMS by users.

\section{PENDAHULUAN}

Semakin berkembang pesatnya
teknologi sejalan pula dengan semakin
berkembangnya kualitas dunia Pendidikan
khusunya jenjang Perguruan Tinggi. Pembelajaran daring atau online melalui $e$ learning yang biasa disebut Learning Management System (LMS) merupakan cerminan kualitas dari Perguruan Tinggi. Pada era yang serba menggunakan teknologi, Perguruan Tinggi harus mampu memanfaatkan peran terknologi tersebut untuk dapat mengembangkan model pembelajaran jarak jauh. Pengembangan Learning Management System (LMS) harus didesain dan dikembangkan secara maksimal untuk menunjang segala keperluan yang dibutuhkan pengguna LMS tersebut yaitu mahasiswa, dosen, dan tenaga kependidikan. Learning Management System (LMS) dinilai baik dan memuaskan abila dapat memfasilitasi mahasiswa, dosen, dan tenaga kependidikan jika mempunyai semua source atau fitur yang dibutuhkan dalam proses pembelajaran dan dapat memberikan segala informasi yang valid yang mana ketepatan, kelengkapan, kecepatan, dan kemudahan akses merupakan hal yang harus diperhatikan oleh Perguruan Tinggi.

Learning Management System (LMS) merupakan suatu perangkat lunak atau software yang digunakan untuk keperluan administrasi, dokumentasi, validasi, laporan, kegiatan pembelajaran dan pembelajaran jarak jauh secara online dan berisi modul atau materi belajar. LMS sebagai mendia pembelajaran berfingsi dalam meningkatkan motivasi belajar dan minat peserta didik dalam mempelajari suatu materi pembelajaran, meningkatkan efektivitas dan efisiensi dari penyampaian informasi, dan kemudahan untuk menerima serta mengolah 
materi pembelajaran. Dapat disimpulkan bawa adanya media pembelajaran dalam hal ini adalah LMS penting untuk membantu peserta didik dalam proses pembelajaran.

Berdasarkan hal tersebut maka perlu pengembangan Learning Management System (LMS) sebagai media pembelajaran online. Diharapkan mampu meningkatkan motivasi belajar dan minat peserta didik dalam mempelajari suatu materi pembelajaran, meningkatkan efektivitas dan efisiensi dari penyampaian informasi, dan kemudahan untuk menerima serta mengolah materi pembelajaran serta dapat diimplementasikan pada proses pembelajaran untuk melihat bagaimana efektivitas penggunaan Learning Management System (LMS). Pada LMS terdapat ruang lingkup administrasi, dokumentasi, validasi, laporan, kegiatan pembelajaran dan pembelajaran jarak jauh secara online dan berisi modul atau materi belajar yang dikemas dalam multimedia (teks, animasi, video, audio) dapat mempercepat dan meningkatkan penguasaan materi pembelajaran oleh peserta didik hingga secara tidak langsung meningkatkan kualitas pembelajaran secara maksimal.

\section{KAJIAN LITERATUR}

\section{Model Pengembangan Addie}

Model pengembangan dari Analysis, Design, Development or Production, Implementation or Delivery, and Evaluation atau disingkat ADDIE. Model ADDIE dapat digunakan untuk mengembangkan macammacam bentuk pengembangan produk seperti model, strategi pembelajaran, metode pembelajaran, media, dan bahan ajar. Dua orang pakar yang turut mengembangkan konsep ADDIE adalah Reiser dan Molenda. Molenda menyatakan bahwa revisi dapat terjadi terus menerus dalam setiap tahap yang dilalui walaupun tidak dinyatakan secara jelas (Prawiradilaga, 2012). Model ADDIE dipilih pada penelitian pengembangan ini karena model ini merupakan model desain pembelajaran yang berorientasi produk. Model ADDIE dapat digunakan untuk mengembangkan berbagai produk, seperti model, strategi pembelajaran, metode pembelajaran, media dan bahan ajar (Wiyani \& Ratri, 2016).

Desain Pengembangan Pembelajaran Model ADDIE adalah salah satu proses pembelajaran yang bersifat interaktif dengan tahapan-tahapan dasar pembelajaran yang efektif, dinamis dan efisien. Model ini kemudian dapat digunakan untuk berbagai macam bentuk pengembangan produk seperti strategi dan metode pembelajaran, media dan bahan ajar termasuk disini adalah Learning Management System (LMS). Model ADDIE dapat menjadi pedoman dalam membangun perangkat dan infrastruktur program pelatihan atau model pembelajaran yang efektif, dinamis dan mendukung pencapaian tujuan desain pembelajaran itu sendiri dengan beberapa tahapan.

Menurut Anita Trisiana dan Wartoyo berikut Langkah atau tahapan dalam Model ADDIE (Trisiana \& Wartoyo, 2019):

1. Analyze (Analisis), pada tahapan ini dilakukan analisa tentang beberapa hal yang perlu diketahui sebelum kegiatan pelatihan dilakukan. Seperti tujuan penyelenggaraan training, siapa peserta dan apa yang menjadi kebutuhan peserta training terkait dengan materi, metode, teknik 
pembelajaran, dan lain-lain.

2. Design (desain), dalam tahap desain ini seorang perancang pelatihan perlu melakukan perencanaan awal untuk program pelatihan/pembelajaran, perancangan materi pelatihan dan perencanaan evaluasi pelatihan secara konseptual yang nantinya akan dijadikan dasar dalam tahap pengembangan.

3. Develop (pengembangan), pada tahapan ini kegiatan dilakukan dengan merealisasikan konsep yang sudah dibuat pada tahap disain. Kegiatan pengembangan adalah merealisasikan kerangka yang dibuat dalam bentuk materi pelatihan, persiapan peralatan yang akan digunakan dan pembuatan evaluasi pelatihan.

4. Implement (implementasi), tahapan implementasi adalah tahapan dimana program pelatihan dilaksanakan. Program pelatihan dilakukan sesuai rencana yang sudah dibuat.

5. Evaluate (evaluasi), tahap akhir adalah evaluasi. Evaluasi dilakukan guna meninjau kembali pelaksanaan pelatihan apakah sudah sesuai dengan kebutuhan atau tidak. Kemudian evaluasi juga digunakan oleh perancang pelatihan untuk memperbaiki kekurangan metode yang akan digunakan, sehingga kegiatan pembelajaran kedepannya dapat dirancang dengan lebih baik lagi.

\section{Learning Management System (Lms)}

Learning Management System (LMS)

merupakan suatu aplikasi atau software yang digunakan untuk mengelola pembelajaran online yang meliputi beberapa aspek yaitu materi, penempatan, pengelolaan, dan penilaian (Mahnegar, 2012). Selanjutnya Learning Management System (LMS) atau Course Management System (CMS) yang mana juga dikenal sebagai Virtual Learning Environment (VLE) merupakan aplikasi perangkat lunak yang digunakan oleh kalangan pendidik, baik universitas atau perguruan tinggi dan juga sekolah sebagai media pembelajaran online berbasis internet (e-learning).

Menurut Darin E. Hartley yang dikutip oleh Adri menyatakan definisi elearning sebagai berikut yaitu suatu jenis belajar mengajar yang memungkinkan tersampaikannya bahan ajar ke siswa dengan menggunakan media internet, intranet, atau media jaringan computer lain (Adri, 2007). Sedangkan pada LearnFrame.com dalam Glossary of e-learning dalam Adri menyatakan definisi e-learning secara lebih luas yaitu sistem pendidikan yang menggunakan aplikasi elektronik untuk mendukung belajar mengajar dengan media internet, jaringan komputer, maupun komputer stand alone (Adri, 2007).

Menurut Rusman e-learning memiliki karakteristik-karakteristik sebagai berikut (Rusman, 2013):

1. Memanfaatkan jasa teknologi elektronika; di mana guru dan siswa, siswa dan sesama siswa atau guru dan sesama guru dapat berkomunikasi dengan relatif mudah dengan tanpa dibatasi oleh halhal yang protokoler.

2. Memanfaatkan keunggulan komputer (digital media dan computer networks).

3. Menggunakan bahan ajar bersifat mandiri (self learning materials) disimpan di komputer sehingga dapat diakses oleh guru dan siswa kapan saja dan di mana saja bila yang bersangkutan memerlukannya.

4. Memanfaatkan jadwal pembelajaran, kurikulum, hasil kemajuan belajar dan hal-hal yang berkaitan dengan administrasi Pendidikan dapat dilihat setiap saat di komputer.

\section{METODE PENELITIAN}

Dalam penelitian ini menggunakan metode penelitian dan pengembangan atau biasa disebut R\&D (Research and 
Development). Metode penelitian dan pengembangan (Research and Development) juga didefinisikan sebagai penelitian yang secara sengaja, sistematis, bertujuan/diarahkan untuk mencari temuan, merumuskan, memperbaiki, mengembangkan, menghasilkan, menguji efektivitas produk, model, metode/strategi/cara, jasa, prosedur tertentu yang lebih unggul, baru, efektif, efisien, produktif, dan bermakna (Putra, 2017). Research and Development (R\&D) merupakan metode penelitian yang digunakan untuk menghasilkan suatu produk tertentu, dan menguji efektivitas produk tersebut (Sugiyono, 2013).

Model pengembangan pada penelitian ini adalah model ADDIE (Analysis, Design, Development, Implementation, Evaluation), yang mana digunakan untuk mengembangkan berbagai produk, seperti model, strategi pembelajaran, metode pembelajaran, media dan bahan ajar (Wiyani \& Ratri, 2016). Model ADDIE dipilih dalam penelitian pengembangan Learning Management System (LMS) karena model ini dilakukan secara sistematis memberikan kesempatan untuk melakukan evaluasi dan revisi secara berkala dan terus-menerus dalam setiap tahapan yang dilalui sehingga Learning Management System (LMS) yang dihasilkan akan menjadi media pembelajaran yang tepat guna.

\section{HASIL DAN PEMBAHASAN}

Hasil penelitian dengan pengembangan model ADDIE yang telah dilaksanakan adalah sebagai berikut.

\section{Analyze (Analisis)}

Melakukan analisis kompetensi, analisis karakteristik sumber daya manusia (SDM), dan analisis instruksional yang mana dari perguruan tinggi menemukan permasalahan di lapangan terkait pengembangan dan pelaksanaan pembelajaran daring. Hal ini ditindaklanjuti dengan pengumpulan data melalui kunjungan dan observasi kelas, wawancara dan pemberian angket kepada para dosen. Diharapkan melalui tindak lanjut ini, akan diperoleh gambaran yang riil tentang kondisi permasalahan tersebut dan akan menjadi masukan untuk tindakan selanjutnya yang harus dilaksanakan.

Berikut ini adalah temuan dari hasil pengumpulan data:

\section{- PERMASALAHAN}

1. Dosen kesulitan dalam menciptakan suasana diskusi yang aktif antar mahasiswa terkait materi perkuliahan dalam pembelajaran daring.

2. Dosen kesulitan mengeksplorasi aktivitas yang menarik yang harus dikaitkan dan dikembangkan sesuai materi ajar agar mahasiswa antusias terhadap materi pembelajaran.

3. Dosen kesulitan dalam melakukan pemetaan kompetensi mahasiswa untuk menentukan penerapan metode pembelajaran yang sesuai.

4. Dosen kesulitan melakukan asistensi kepada mahasiswa dalam mata kuliah praktek.

5. Dosen kesulitan melakukan monitoring dalam proses mahasiswa mengerjakan tugas yang telah diberikan.

6. Dosen kesulitan menentukan indikator tercapainya capaian pembelajaran oleh mahasiswa sudah sesuai rencana pembelajaran semester (RPS) atau belum.

7. Dosen belum memahami konsep mengajar daring yang efektif dan efisien. 
- PROFIL DOSEN:

Berdasarkan lama mengajar:

1. $40 \%$ dosen adalah baru dan fresh graduated (pengalaman pertama mengajar)

2. $35 \%$ dosen yang telah mengajar 2 tahun atau lebih

3. $25 \%$ dosen yang telah mengajar selama 5 tahun atau lebih

Berdasarkan jenjang pendidikan:

1. $65 \%$ dosen dengan pendidikan terakhir S2

2. $35 \%$ dosen dengan pendidikan terakhir S3

Berdasarkan jenjang jabatan akademik:

1. $40 \%$ dosen adalah tenaga pengajar atau belum memiliki jabatan akademik

2. $35 \%$ dosen memiliki jabatan akademik Asisten Ahli

3. $25 \%$ dosen memiliki jabatan akademik Lektor, Lektor Kepala

\section{- PROFIL LINGKUNGAN}

1. Kampus berada di perkotaan mandiri milik swasta, dekat dengan pusat bisnis serta berada diantara perumahan modern (cluster) dan perumahan biasa.

2. Lingkungan kota belum terlalu ramai dan banyak penduduk merupakan pendatang dari luar kota.

3. Area Kampus cukup luas dan asri, banyak area hijau dan tempat mahasiswa berkumpul.

\section{- FASILITAS KAMPUS}

1. Sistem Informasi Akademik (SIAKAD) masih baru diimplementasikan dan dikembangkan.

2. Learning Management System (LMS) masih baru diimplementasikan dan dikembangkan juga belum semua dosen menggunakan LMS tsb.

3. Wi-fi untuk mahasiswa tersedia dalam bandwidth rendah.

\section{- PENGEMBANGAN WAWASAN DAN KEILMUAN}

Terdapat $70 \%$ dosen yang merasa membutuhkan penyesuaian dan pelatihan pembuatan rencana pembelajaran semester (RPS) yang disesuaikan dengan pembelajaran daring di LMS.

\section{Design (Desain)}

Berdasarkan hasil analisis, maka diputuskan bahwa rencana pembelajaran semester (RPS) merupakan komponen dasar dalam pengembangan serta implementasi Learning Management System (LMS) sebagai media pembelajaran. Rencana pembelajaran semester (RPS) harus sesuai dan memuat skema pembelajaran semester serta capaian pembelajaran mata kuliah. Seluruh dosen akan mengikuti pelatihan pembuatan RPS yang disesuaikan dengan pembelajaran daring di masa normal atau pandemi. Pihak perguruan tinggi dan trainer merancang pelatihan yang muatan materinya disesuaikan dengan kebutuhan para dosen. Merancang suatu tahap pembelajaran merupakan hal yang harus dilakukan terlebih dahulu sebelum kita mengembangkan LMS, sehingga kita dapat mengidentifikasi fiturfitur apa saja yang diperlukan di LMS sebagai media pembelajaran.

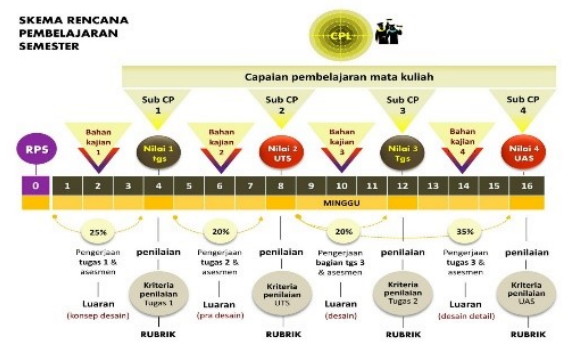

Gambar 2 Skema Pembelajaran Semester

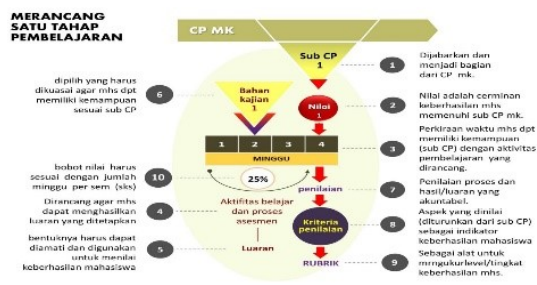

Gambar 3 Merancang Satu Tahap Pembelajaran 
Selanjutnya adalah melakukan rancangan rencana sosialisasi implementasi Learning Management System (LMS)) untuk mengetahui kebutuhan dan kendala yang dihadapi pengguna LMS dalam proses pembelajaran.

1. Sasaran, yang mana seluruh dosen wajib mengikuti pelatihan pelatihan pembuatan rencana pembelajaran semester (RPS) yang disesuaikan dengan pembelajaran daring di masa normal maupun pandemi dimulai dari hal dasar dalam metode pembelajaran (landasan dan hal-hal mendasar untuk menguatkan pemahaman dosen).

2. Materi yang akan diberikan pada pelatihan harus sesuai dengan hasil analisis maka ditentukan materi, durasi, landasan dasar pembuatan, pemanfaatan Learning Management System (LMS), evaluasi hingga refleksi.

3. Waktu pelatihan: 2 (dua) hari, 8 jam perhari

4. Metode: Presentasi, diskusi kelompok, simulasi, games

5. Media: Infocus, audio, papan tulis besar, spidol, papan tulis kecil, sticky note, laptop

6. Sarana: Ruangan tertutup atau semi tertutup sesuai dengan jumlah peserta

\section{Development (Pengembangan)}

Berdasarkan hasil analisis dan desain yang telah disusun, pihak perguruan tinggi dan tim pengembangan Learning Management System (LMS) melakukan kajian materi dan mengembangkan modul pelatihan penggunaan LMS dengan mengidentifikasi fitur-fitur yang ada bagi dosen dan mahasiswa, menyiapkan lembar kegiatan atau teknik evaluasi tiap fitur pada LMS, dan menyiapkan sumber belajar lainnya yang perlu dikombinasikan di LMS sesuai dengan kebutuhan dosen.

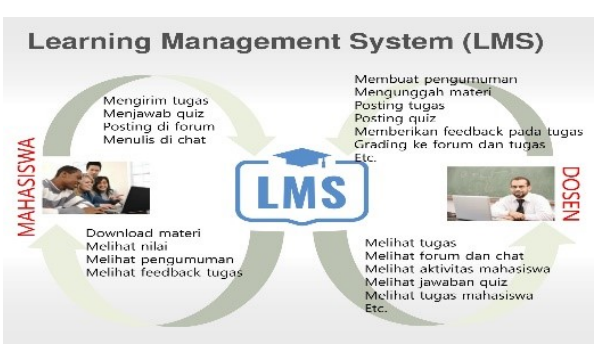

Gambar 4 Identifikasi Fungsi LMS

\section{Implementation (Implementasi)}

Implementasi adalah langkah nyata untuk menerapkan sistem dan desain pelatihan serta penggunaan LMS yang telah disusun dan terintegrasi sehingga tujuan tujuan yang telah ditetapkan sebelumnya bisa tercapai dengan baik.

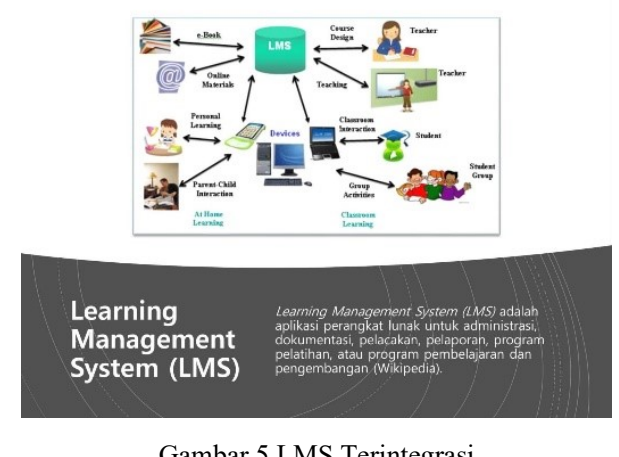

\section{Evaluation (Evaluasi)}

Evaluasi adalah sebuah proses yang dilakukan untuk memberikan nilai dan masukan terhadap program pembelajaran. Pada model ini, evaluasi yang yang dilakukan adalah:

\section{- EVALUASI FORMATIF}

1. Setiap selesai melakukan proses pada setiap tahapan.

2. Setiap selesai materi pelatihan dilakukan evaluasi dengan cara membagikan kertas evaluasi dan refleksi. Dalam kegiatan ini peserta diminta menuliskan beberapa hal/kata/kalimat kunci dari materi yang disampaikan untuk mengecek pemahaman dan refleksi dari para peserta terkait kebermanfaatan materi dan fitur-fitur yang ada di Learning Management System (LMS) yang 
disampaikan kaitannya dengan kebutuhan proses pembelajaran.

3. Simulasi mengajar (microteaching) dan pembuatan RPS yang pada akhir kegiatan.

4. Evaluasi untuk seluruh materi yang telah diberikan pada akhir pelatihan penggunaan dan pengembangan LMS serta masukan terkait kendala serta tambahan fitur di LMS oleh pengguna.

\section{- EVALUASI SUMATIF}

Mengevaluasi keberhasilan program pelatihan dan evaluasi penggunaan Learning Management System (LMS) dengan cara melakukan evaluasi langsung di kelas perkuliahan. Dalam 2 bulan, secara terjadwal pihak sekolah melakukan:

1. Monitoring dan pendampingan di kelas saat penyusunan RPS yang implementasinya sudah sesuai dan ditunjang dengan penggunaan LMS.

2. Monitoring dan pendampingan kegiatan pembelajaran dalam kelas perkuliahan dengan menggunakan LMS.

\section{KESIMPULAN}

Berdasarkan hasil penelitian dan pengembangan Learning Management System (LMS) sebagai media pembelajaran yang telah diimplementasikan, maka diperoleh kesimpulan sebagai berikut:

1. Penelitian dan pengembangan ini menghasilkan sebuah pembaruan pada Learning Management System (LMS).

2. Pengembangan Learning Management System (LMS) sebagai media pembelajaran telah melalui tahap validasi oleh para pengguna, dengan melakukan evaluasi langsung di kelas perkuliahan. Tahap ini merupakan analisis kebutuhan dimana dilakukan evaluasi kondisi proses pembelajaran menggunakan LMS yang terjadi sebelum dan setelah dilakukan pengembangan LMS.

3. Efisien dan efektivitas penggunaan Learning Management System (LMS) sebagai media pembelajaran dalam proses pembelajaran dapat dilihat dari keterlaksanaan penggunaan LMS yang mana secara keseluruhan berjalan dengan baik. Ini terlihat dari hasil respon dosen yang menunjukkan bahwa Learning Management System (LMS) sebagai media pembelajaran yang telah dikembangkan ini termasuk pada kategori "sangat praktis".

\section{REFERENSI}

Adri, M. (2007). Strategi pengembangan multimedia instructional design (suatu kajian teoritis). Jurnal Invotek, $\operatorname{VIII}(1)$.

Prawiradilaga, D. S. (2012). Wawasan Teknologi Pendidikan. Kencana Prenada Media Group; Prenada media group. http://inlislite.uinsuska.ac.id/opac/detail-opac?id $=65$

Putra, N. (2017). Research \& Development Penelitian dan Pengembangan: Suatu Pengantar. In PT Raja Grafindo Persada (Vol. 4, Issue 2). Rajawali pers.

Rusman. (2013). Belajar dan Pembelajaran Berbasis Komputer Profesionalisme. Alfabeta.

Sugiyono. (2013). Metode Penelitian Kuantitatif, Kualitatif dan Kombinasi. Edisi Keempat. Alfabeta.

Trisiana, A., \& Wartoyo. (2019). Desain Pengembangan Model Pembelajaran Pendidikan Kewarganegaraan Melalui ADDIE Model Untuk Meningkatkan Karakter Mahasiswa di Universitas Slamet Riyadi Surakarta. Jurnal PKn Progresif, 11(1), 313-330.

Wiyani, N. A., \& Ratri, R. K. (2016). Manajemen Kelas: Teori Dan Aplikasi Untuk Menciptakan Kelas Yang Kondusif (Vol. 2016). Ar-Ruzz Media. 